\title{
EVALUATION OF THE IMPACT AND IMPORTANCE OF INFORMATION SHARING IN THE AVIATION SECTOR WITH TWO DIFFERENT QUALITATIVE ANALYSIS
}

\author{
DOI: 10.17261/Pressacademia.2021.1391 \\ RJBM- V.8-ISS.1-2021(3)-p.27-36
}

\author{
Abdullah Turk \\ Istanbul Gelişim University, Faculty of Economics, Administrative and Social Sciences, Istanbul, Turkey. \\ abturk@gelisim.edu.tr, ORCID: 0000-0002-2804-4203
}

\begin{tabular}{l}
\hline Date Received: January 15, $2021 \quad$ Date Accepted: March 27, 2021 \\
\hline To cite this document \\
Turk, A. (2021). Evaluation of the impact and importance of information sharing in the aviation sector with two different qualitative analysis. \\
Research Journal of Business and Management (RJBM), V.8(1), p.27-36. \\
Permanent link to this document: $h$ ttp://doi.org/10.17261/Pressacademia.2021.1391 \\
Copyright: Published by PressAcademia and limited licensed re-use rights only.
\end{tabular}

\section{ABSTRACT}

Purpose- Aviation has an important place in the world economy. The correct management of operations in this sector is equivalent to the correct management of financial resources. Operations in aviation are a combination of very complex relationships. Effective information sharing and communication cohesion play a vital role in these relationships. This study focuses on the impact and importance of information sharing in aviation on team communication.

Methodology- The study is handled from the perspective of knowledge-based theory and learning organization. The study was conducted through semi-structured interviews with 15 senior operations managers in aviation. The data obtained from these interviews were analyzed in two different qualitative data programs, NVivo 12 and Maxqda 20.

Findings- As a result of the study, an intense relationship was found between criteria such as coordination, organizational success, operational success and effective decision making.

Conclusion- As a result of the study, a cycle was determined. It has been concluded that the impact of information sharing in aviation on team communication and the continuity of operational success supports the organizational success with coordination efficiency in the long term.

Keywords: Information sharing, team communication, organizational learning, aviation sector. JEL Codes: 015, 019, M12

\section{INTRODUCTION}

The aviation sector has a very important place in the world economy. The information and technology infrastructure of the sector is brought along to be affected quickly by change. The most important point in this sector is to be able to properly spread this information to the system. Organizations in this sector manage large-scale activities. However, these activities are the sum of the operations of very different small teams. Considering the information-based structure of the sector, every operation needs information sharing. This sharing means a serious communication network. In this respect, the operational success of the subunits is considered important in the success of the organization. However, in this sector, sub units require different skills to be used at the same time. In this respect, the study has two interdependent objectives.

First of all, it is to measure the infrastructure of the focus group that is researched on information sharing and team communication in aviation, related to the conceptual aspect of the subject. This measurement is considered from the point of view of the managers of information sharing and team communication. Another aim of the study is to reveal the passwords determined by the managers in the effect of sharing information on team communication.

In this study, it is aimed to present a perspective on the issue of information sharing by feeding from knowledge-based theory and team communication by feeding from learning organizations. The nature of aviation is also emphasized in the study. In the second part of the study, categories were created using the phenomenology method in order to understand the conceptual skills of the people who are in managerial positions in operational activities in the aviation sector. Content analysis method was used to 
understand the relationships between the concepts obtained from the category result. Nvivo 12 program was used to demonstrate the phenomenological method. In order to understand the relationship between the concepts revealed, two different qualitative analysis techniques were used by using the Maxqda 20 program.

In the conceptual framework of this study, first of all, as information sharing requires a certain infrastructure, a theoretical support from knowledge-based theory to information sharing has been attempted.

Organizational skill effective in sharing information is communication. For this reason, the fact that aviation operations consist of the activities of teams that are different from each other and small in number within the organization makes it necessary to share information consciously. The consciousness mentioned here is the transfer of knowledge by learning. Therefore, the subject of team communication is handled from the learning organization perspective.

In the last part of the conceptual framework, the nature of aviation was conveyed through the focus of information sharing and team communication.

\section{CONCEPTUAL FRAMEWORK}

\subsection{Knowledge-Based Theory to Knowledge Sharing}

It is not easy to define information. Knowledge constitutes an area where even important thinkers in history cannot reach consensus since Plato (Grant, 1996). Knowledge is the process of making information meaningful after integrating with experience and values to provide a new perspective to expert opinions (Brakensiek, 2002). In this respect, information is the processed form of information. The nature of knowledge directs power relations and creates motion energy with sharing. In this respect, sharing all of the static resources of the enterprises can reveal energy.

Especially in a systematic and formal format, the information that is accepted to be accurate, documented, archived, easily accessible and transferred by every employee is called open information. The sharing of this open information points to technical knowledge (know-how) that are not easily accessible. On the other hand, information that is a whole in terms of values and more valuable for the organization shared through social interaction is called implicit knowledge sharing (Bruning et al., 1999). At this point, knowledge-based theory makes a deep distinction between explicit knowledge and types of implicit knowledge. Implicit knowledge; While explicit knowledge is defined as knowledge that exists only in one's own mind; It is clearly visible in the organizational setting. It is possible to make this distinction as follows; When asked what techniques a cycling bike uses, the person cannot answer the questions theoretically, but can still ride a bike without any problems (Polanyi, 1997). Explicit knowledge, on the other hand, is information that can be fully defined and systematically presented. Knowledge according to the knowledgebased theory; It is preserved at the individual level, but has a collective character through knowledge-based actions, integration mechanisms, and coordination of organization members (Simon, 1991). The ability of the aforementioned knowledge to generate motion energy is fed by this theory.

The way organizations can manage their knowledge can determine their success or failure (Miles 2012). At this point; Thanks to organizational integration and coordination mechanisms, the obstacles brought by the limited rationality of individuals to organizations can be overcome. For this reason, organizations are considered as entities that provide the necessary information integration for the application of individual knowledge, beyond being entities that create, store and use information (Simon, 1991). Individuals carry the knowledge acquired through the act of learning to the organizational level with organizational procedures, rules, norms and structures. The main task of organizations is to be able to coordinate the efforts of individuals with different specialized knowledge and to ensure information integration. Organizations are social entities that hide, integrate and use in-house knowledge, skills and abilities that are vital for survival, growth and success (Grant, 1996). This point is knowledgebased theory; It examines how organizational performance differs depending on the organization's main resources or technical (know-how) knowledge (Miller 2002). The research underlying this theory has focused on the role, importance and organizational outcomes of sharing knowledge for organizations.

At this point, organizations have the task of applying and using knowledge, as well as obtaining and creating knowledge. In particular, knowledge-based theory focuses on the coordination of organization members for the use of knowledge and the integration of their specialized knowledge in a concerted effort. In this direction, the theory examines how the organizational need for improving the coordination and harmony of the employees in the learning process can be met (Kogut \& Zander, 1992). This role of sharing knowledge in knowledge-based theory also supports the learning organization structure, which is constructed as a theoretical basis for team communication activity, which is another variable of the study. 
According to the knowledge-based theory; information is not only a strategic resource that provides a sustainable competitive advantage. It has a special structure that enables organizations to have knowledge-based capabilities. With this aspect, information; organizational culture is an asset that can be transferred, stored and processed through structures such as identity, norms and routines (Keskin, 2016). In this respect, businesses can reveal energy by sharing intangible resources in static state.

In this respect, information sharing is based on factors that have active interaction among determinants such as motivation, communication, coordination, organizational structure, culture, incentives, needs, and most importantly, trust (Steinheider and Al-Hawamdeh, 2004: 1-2). At this point, it can be said that information sharing is a tool for management to capture functional efficiency.

Knowledge is important in the organizational structure as it enables everyone to share their individual values. Language, symbolic communication tools, shared specialist knowledge, shared meaning and mutual harmony make up various common types of knowledge. At this point, organizations' sharing of information plays an important role (Dandridge et al, 1980). Information sharing is generally explained as the activities of transferring, coding and interpreting information from one person or group to another person or group (Linn \& Lee, 2005). Knowledge sharing provides mechanisms that can be rearranged to create organizational value and solve problems, and transform individual knowledge into organizational knowledge. This sharing is a guide for activities and decisions (Gupta et al., 2007: 71). At this point, sharing information; It provides a task-related technical benefit in solving problems, developing new ideas, implementing policies and procedures, and cooperating (Cummings, 2004). The purpose of information sharing includes organizational learning and the formation of a culture of joint problem solving (Abidi, 2006: 67). At this point, Gold et al. (2001) concluded in their study that organizational effectiveness is closely related to the knowledge management process. Chang Lee et al. (2005) argue that this process consists of knowledge production, accumulation, sharing, use and internalization. Understanding how knowledge is obtained and shared is important for organizational success (Galunic et al., 2014). At this point, various researchers reported that knowledge sharing has a key role in achieving organizational success (Alavi \& Leidner, 2001).

\subsection{Learned Organization to Team Communication}

Communication; It refers to the transfer of information, request or a message from a source to the recipient (Taylor and Cooren, 1997: 420). Communication is a process that affects organizational performance both directly and indirectly (Garnett, et al .; 2008: 266). Managers; He conveys what, how and when to do to his subordinates through the communication process. Organizational communication is the process of changing employees' attitudes or influencing their behavior through information (Kelly, 2000: 92). Organizations are divided into various functions within themselves. The most important tool that determines the success of the organization is the quality of the communication between these functions. The main reason for organizational functions to be in communication is to provide the ability to act together. This ability, which is defined as coordination in the literature, is also the most important function of management that includes movement. From this point of view, we can say that the communication process is a dynamic process. Within these dynamic processes, even in the same department, there are parts, groups, teams and teams that are intertwined with each other. Especially in sectors with predominant operational functions, sub-teams and teams are frequently encountered. The ability to achieve quality in total is often hidden in the harmonious and effective relationship of these sub-units. The success of the teams depends on the sharing of the information obtained as a result of teamwork.

As a matter of fact, according to Fleming and Monda-Amaya (2001: 159), for the effectiveness of teamwork, members of the team must share the information. This information should be fully and accurately communicated to all team members, because the effectiveness of teams is in a structure that increases with information sharing. Any information shared with team communication needs to support the success of the team. Therefore, it is very important that the communication between the team members is compatible (Hayashi, 2004). Basically, very fast information exchanges take place within this network of relationships. This exchange of information spreads from the bottom to the top in an interconnected way.

As the teams work in connection with each other; It supports employees to communicate and collaborate in order to learn new methods or ways (Garvin, 1993). As a result of this exchange, organizations realize learning as a result of the activities and interactions of people working in small teams. At this point, learning teams constitute an important link between learners and learning organizations (Senge, 1990a: 236). At this point, Hidalgo (2011, p. 2) states that "the ability of a firm to be productive depends not only on the skills of its employees, but also on the way they interact". This interaction progresses from the bottom up and is provided by the communication of the teams, which are the lowest unit. Sharing knowledge also offers the opportunity to evaluate every known knowledge at an organizational level. This structure, which creates a transitive memory, can support the learning process of organizations and thus support the learning organization structure with information sharing, team communication. 
Indeed, Senge (1990); He suggests that it is possible for an organization to become a learning organization, by activating individual information within the teams established within the enterprise, and transforming it into "team learning" through the interaction of members and moving from there to the organizational dimension. At this point; One of the characteristics of successful teams is the ability to see together. Learning teams become working groups that develop themselves and their organizations by learning from each other, from the process and the results, while conducting their work in line with their shared goals, interacting with each other and with their environment, using the expertise and experience of their members.

Hamel (1999) states that team members working in interaction with each other will eliminate the deficiencies and provide integrity. It also emphasizes that with this union, members will reach faster thinking and learning that complement each other. At this point, Jensen (2003) and Potter (2003) argued that information communication at organizational level plays an important determinant role in organizational integration and success in different studies. Organizational level communication; supports functions such as information sharing, feedback of transmitted messages, coordination of different functions, persuasion, sharing feelings and innovation (Bolarinwa and Olorunfemi, 2009: 2). In De Vries and Van den Hooff (2006); He stated that sharing information has an effect on communication, job satisfaction and performance among team members.

\subsection{Nature of the Aviation Industry}

This study has been applied especially in the aviation industry, where operational activities take place intensely. As it is known, this sector has a deep information infrastructure and the effect of continuous change. This change brings a serious flexibility requirement to the sector. Aviation is the most reliable transportation sub-branch as transportation. However, there is almost no chance to survive accidents in this sector. Moreover, the death rate in a single accident is very high. This shows how little error margin of the sector is. At this point, it is vital that information is shared effectively from lower units to upper units. This means that information sharing and team communication efficiency in the sector is at the highest level without any room for error. In this respect, understanding the nature of the sector in which the application is performed is considered valuable in terms of revealing the nature of the study.

In aviation, the relationship between the members of a team or team, such as collecting and sharing information, planning, leadership, effective decision making and identification, management of errors and problems, is provided through communication (Nevile 2006: 5). There are many findings showing the critical importance of communication in ensuring safety in aviation. Sexton and Helmreich (2009) state that operational communication is fundamental to the safe and efficient results of any flight. Thus; It is known that communication plays an important role in aviation accidents and incidents. Accidents and incidents in aviation are human-induced rather than mechanical errors. According to industry statistics, while the human-induced error rate for accidents and incidents in airline transportation is close to $80 \%$, the rate of mechanical and other errors is $20 \%$ (FAA 1999: 3). In addition, $60-70 \%$ of all aviation accidents are caused by ineffective communication and other communication-related deficiencies (FAA 2004: 4). From this point of view, the lack of communication is vital for the aviation industry, which has a dense information infrastructure. At this point, due to the nature of the sector, it has a multinational structure. It has been stated in some studies that sharing knowledge and learning activities may be a limiting factor with this national culture effect (Husted and Michailova, 2002: 20; Riege, 2005: 25). Of course, it is not possible to say that every piece of information is important. However, the important thing is that correct transfer of information provides operational success. At this point, many activities at operational level, from start-up procedures to finishing procedures, are independent from each other. However, the efficiency of coordination in this sector, which carries out its activities by integrated teams, is possible with the sharing of information and the efficiency of communication. As a matter of fact, almost all aviation operations that took place smoothly were successful thanks to the performance of approving information at every step. At this point, the most important resources are the written, controllable and accessible reports of all team activities that take place in the air and on the ground due to the nature of aviation.

\section{METHODOLOGY}

This study focuses on the impact and importance of information sharing on team communication in the aviation industry. For this purpose, categories were created using the phenomenology method to understand the conceptual skills of the people who are in managerial positions in operational activities in the aviation sector. Content analysis method was used to understand the relationships between the concepts obtained as a result of the category. Nvivo 12 program was used to demonstrate the phenomenological method. In order to understand the relationship between the concepts revealed, two different qualitative analysis techniques were used by using the Maxqda 20 program. 


\subsection{Method and Sampling}

Phenomenology method mostly involves collecting data through clinical interview, but it is possible to collect individuals' experiences or thoughts about concepts through group interviews, observations, answers to open-ended questions, drawings, and historical documents (Marton, 1994). The reason for using NVivo software in this method; It provides advanced tools for visualizing data by allowing deep analysis (Patton, 2002). This software has the capacity to analyze, classify and categorize the data obtained from the interviews (Welsh, 2002). It also enables the researcher to control large amounts of data and create a model for themes and sub-themes (Gibbs, 2002). NVivo is a powerful tool that supports qualitative and mixed method research and can facilitate many aspects of the grounded theory process, from design and sampling procedures to analysis of data, theoretical development, and presentation of findings (Hutchison, Al, 2010).

The purpose of using the MAXQDA 20 program to understand the relationship analysis is; In sampling, focus group interviews (Kitzinger, 1995), which provide the opportunity to form a solid basis with detailed one-to-one interviews with the data, are preferred due to their systematic structure. At this point, MAXQDA provides functions adapted especially for qualitative data analysis of focus group data (Saillard, 2011). In this program; Recorded interviews are written word for word to analyze data from focus groups. Later, it enables codes to be made with the MAXQDA software program (MAXQDA, 2020). The last reason is; This program helps provide intuitive access to statements and contributions from selected participants of the focus group (Kuckartz \& R"adiker, 2019).

\subsection{Data Analysis}

The data obtained as a result of interviews with 15 people working in operational units in the aviation sector were brought together. The phenomena important in operational processes in aviation have been previously investigated in the literature. At this point, the important thing is that the concepts that the managers frequently repeat overlap with the literature and have similar meanings to these concepts. NVivo 12 package was used for data analysis of the information provided by the managers in the documents obtained. The words, sentences and paragraphs in the interview texts are separated according to their usage and frequency. As a result of the interviews of 15 people who have various responsibilities in the aviation industry, the concepts prioritized are "Organizational Success", "Operational Success", "Productivity", "Efficiency", "Effective Decision Making", "Integrity", "Adjustment" and "Coordination". It was understood and these data were transferred in the word find, which is the type of evaluation obtained in the analysis made with Nvivo. The word cloud is shown in Figure 1.

Figure 1: Word Cloud

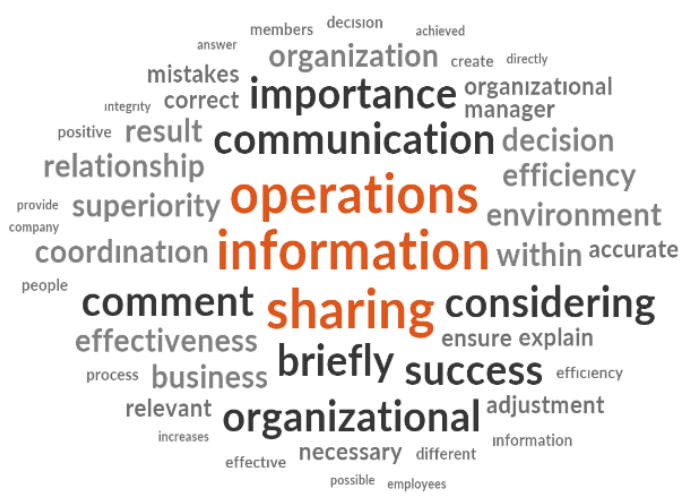

The importance of word cloud in this analysis; It is the creation of a common pool of the most frequently mentioned words among all the words that operational managers use when evaluating the impact of information sharing on team communication. The fact that the words in this pool are bigger or thicker than the other means that the word is emphasized more by the administrators. This is a kind of text analysis of the relationships between information sharing and team communication in aviation organizations.

Another evaluation obtained in the analysis made in the nvivo 12 program is items clustered by word similarity. 
Figure 2: Items Clustered by Word Similarity

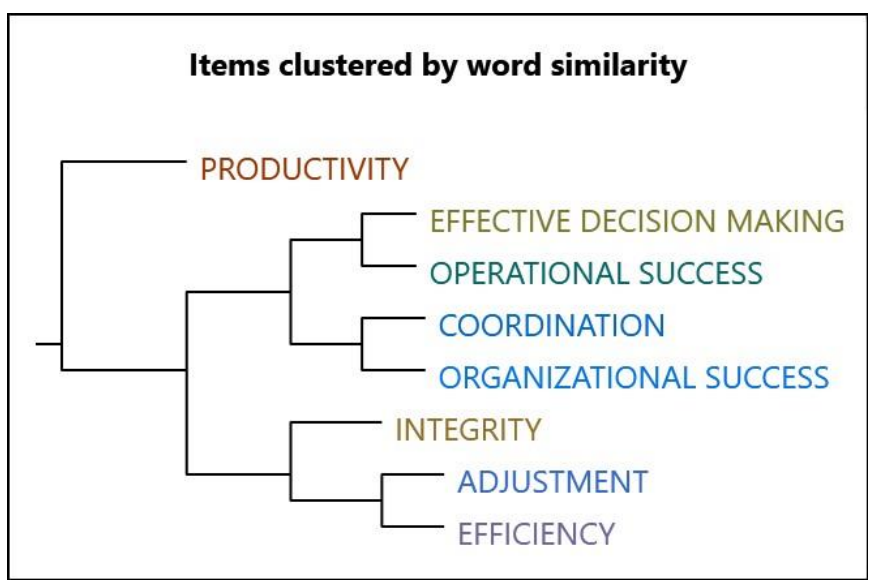

Items Clustered By Word Similarity importance in this analysis; Operational managers use concepts in parallel with the literature in explaining the questions asked while evaluating the impact of information sharing on team communication, and provides information on what concept they support when explaining a concept. The light of this information provides information about the level of conceptual knowledge while explaining a subject that managers are experts in the field. For example; The combined use of the concept of effective decision making and operational success is also frequently mentioned in the list. In addition, coordination and organizational success create conceptual foundations that support each other. It means that these four concepts in total offer conceptual infrastructures that support each other. As a matter of fact, having results parallel to the literature has been a supporting factor in terms of analyzing the relationship between concepts contextually. Therefore; Interviews with operational unit managers in the aviation industry were brought together for content analysis. MAXQDA 20 package was used for data analysis. The data are coded with the program interface, divided into themes and made ready for interpretation. The words, sentences and paragraphs in the interview texts were interpreted and encoded. As a result of the coding process, 8 main codes were determined. These codes are "Organizational Success", "Operational Success", "Productivity", "Efficiency", "Effective Decision Making", "Integrity", "Adjustment" and "Coordination".

Table 1: Code Relationship Browser

\begin{tabular}{|c|c|c|c|c|c|c|c|c|}
\hline Code System & adjustment & coordination & effective decision making & integrity & organizational success & operational success & productivity & efficienc \\
\hline adjustment & & & - & & & & & - \\
\hline$Q_{0}$ coordination & & & ॥ & & & - & & \\
\hline effective decision making & & ! & & &. & 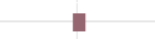 & & . \\
\hline ○ integrity & & & & & & & & \\
\hline organizational success & & & . & & & . & & \\
\hline operational success & & 口 & च & & 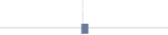 & & & \\
\hline @ productivity & & & & & & & & 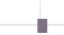 \\
\hline efficiency & - & & ' & & & & - & \\
\hline
\end{tabular}

The relationship between the codes was analyzed according to the coding frequency in the same sentence or paragraph, and the matrix in Table 1 was obtained. According to this analysis, the number of interactions between various codes was quantitatively evaluated. The purpose of the evaluation is to show the strong and weak correlation ties between the codes. These links revealed the elements used by the operational managers participating in the study in their evaluations. According to this matrix; "Coordination" and "Organizational Success" 8 times, "Coordination" and "Operational Success" 4 times, "Operational Success" and "Effective Decision Making" 4 times, "Coordination" and "Effective Decision Making" 3 times, "Efficiency" and "Productivity" 3 times, "Efficiency" and "Adjustment" 3 times were used together and the relationship was transferred. It is possible to mention that the highly interactive codes obtained from these findings create common models and patterns for operational managers working in aviation. According to the relations analysis; In order to achieve success in aviation organizations, the effect of ensuring coordination has come to the fore. At the same time, this situation supports operational success. According to these data, the relationship between being able to coordinate in aviation organizations and effective decision making is high. It is also one of the important findings that effective decision-making within these organizations both supports organizational harmony and affects 
productivity. In addition to these effective relationships, the codes that are less related to each other in terms of impact; There have been "effective decision making" and "adjustment", "efficiency", "coordination" and "productivity". When these codes with low relationship effects were examined, it was observed that some managers avoided putting the two terms together conceptually or used these terms interchangeably. The concepts of "Effective decision making" and "efficiency" are examples of this situation. The reason for this may be the distance of the people working in the sector to academic terms, as well as the fact that words that are close to each other and associated with each other are not used in the same sentence. Another evaluation obtained in the analysis with Maxqda; It is code-based frequency analysis. Code-based frequency analysis; To show to what extent managers interviewed emphasized each code assigned to the study in their text analysis. In the code-based frequency analysis, which was found according to the data obtained from the study, it was determined that managers concentrated on 8 codes at different rates. 93.3\% of the managers focused on "coordination", $86.7 \%$ "organizational success", and $73.3 \%$ "operational success" and "efficiency" code. It is shown in Figure 3.

Figure 3: Code Based Frequency Analysis

\section{Documents with code}

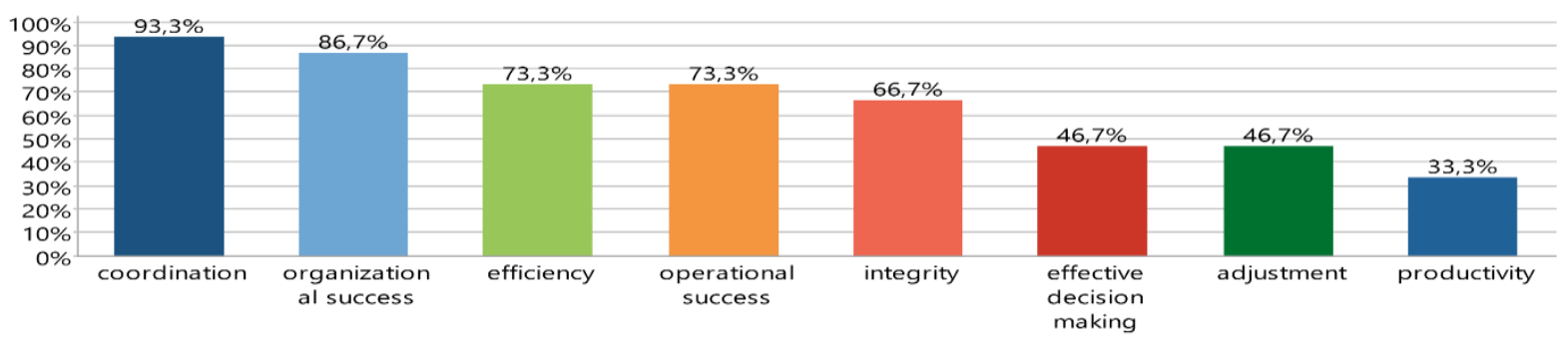

The most important feature of code-based frequency analysis; It can be evaluated as deciphering the password of the work done by the research focus group based on their experience within their expertise. At this point, the focus group, which is a senior manager in aviation and operational processes, is the key to the sector; coordination and organizational success. Another evaluation obtained in the analysis made with Maxqda; it is a single case model analysis. Single case model; It is a single-structured code relationship that emerges as a result of evaluating all the data as a source based on all codes during reading of words, sentences and paragraphs in the texts obtained as a result of the interviews. Single case model; It is a single-structured code relationship that emerges as a result of evaluating all the data as a source based on all codes during reading of words, sentences and paragraphs in the texts obtained as a result of the interviews. This model differs from code-based frequency analysis in that it evaluates all data in a single structure and collects each manager in a single structure. The Maxqda single case model map for coding is presented in Figure 4. 


\section{Single-Case Model}

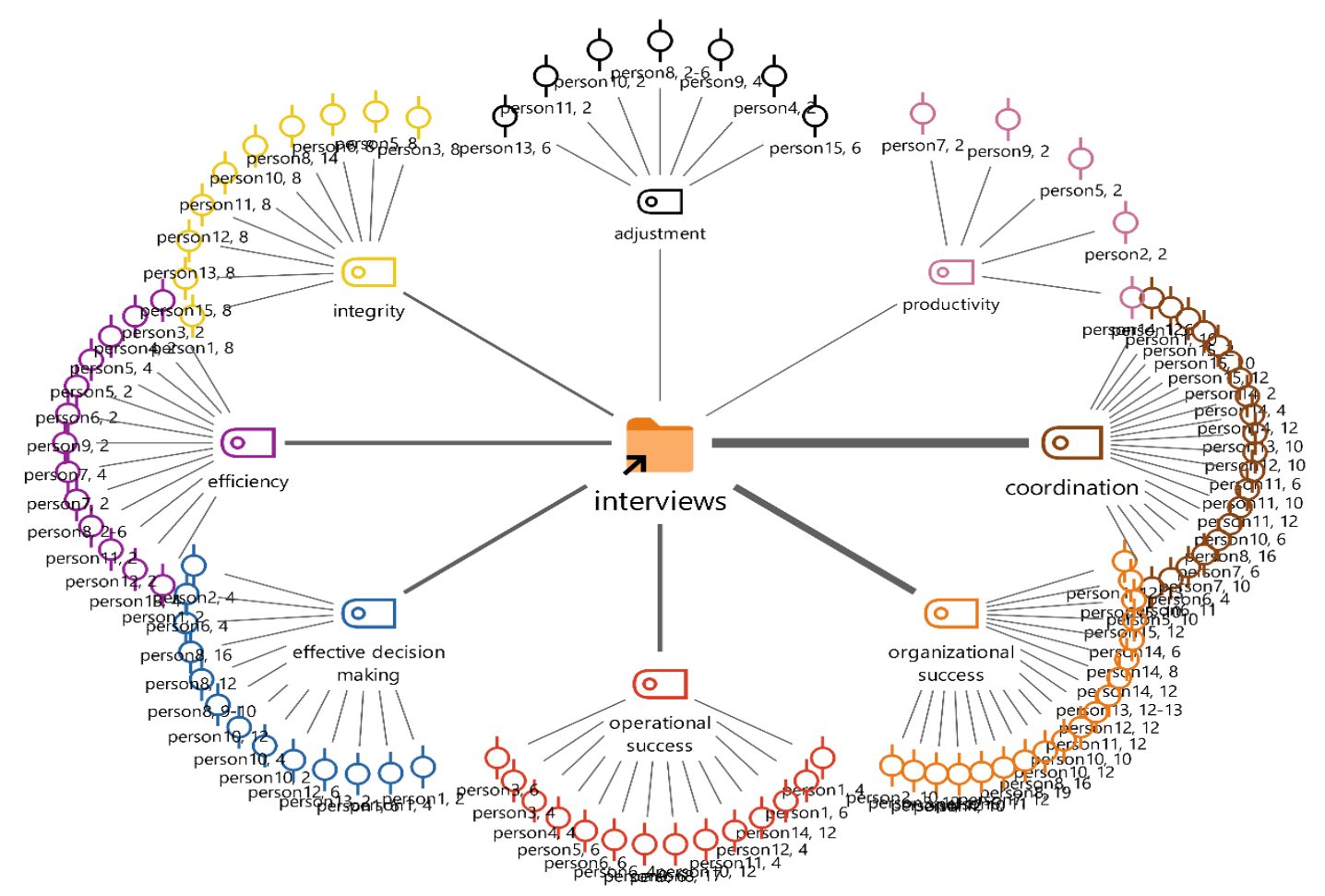

The only case model presented for the study; It conveys the perspective of the interviewed focus group on the impact of information sharing in aviation on team communication. The thickness of the lines emerging from the single structure containing the interview texts transferred in this model towards the codes shows the density of the relationship between the focus group and the relevant code. The quantitative density of the lines coming out of the codes provides the model by detailing the density of the population. According to the single case model, it was determined that the focus group gave the coordination code the main role in the effect of information sharing in aviation on team communication.

\section{CONCLUSION AND DISCUSSION}

The aviation sector has a locomotive feature in the transportation industry. Due to the nature of the sector, more than one operation activity is carried out at the same time. For example, when a passenger plane lands at the airport, on the one hand, incoming passenger operations are carried out, on the other hand, outgoing passenger operations are carried out for the same aircraft. At this point, considering the slot services, gate rights, airport taxes and other costs, it is expected that the difference between the time spent on the ground and the preparation time for reopening is expected to be low. In this respect, it is necessary to manage important information flow in a short time. At the same time, the services of the interface units for the same aircraft are carried out with multiple different team work. At this point, when all flight operations are considered on the same day, the impact of the operational success of aviation companies on the success of the organization seems important. Effective decisionmaking in all processes, accurate evaluations, ability to act in harmony, continuity of safe flight operations are often hidden in the effective communication that sub-units, which are composed of teams, share information. Indeed, Nevile (2006) suggests that information sharing and thus effective decision-making in aviation is possible through communication between the members of a team.

The practical result of this study is that the most important effect of sharing information in operational units in aviation on team communication is hidden in ensuring coordination, which is a management function. Coordination activity stands out as a criterion in supporting organizational success. At this point, a cycle has been determined in the success of aviation organizations. This cycle highlights the coordination relationship between organizational success and operational success, and a process structure that supports effective decision-making is formed. Because the efficiency of the decision mechanism is the basis of coordination. 
However, aviation operations are very intense and continuous. Therefore, some question marks may arise about the continuity of this cycle. At this point, another practical result of the study points to the premise of harmony in information sharing and team communication activity. One of the hidden information of the study is that the relationship of compliance with activity is seen as important in the continuity of this cycle. A general evaluation of results; The effect of information sharing in aviation on team communication is that continuity in operational success supports organizational success with coordination efficiency in the long term.

\section{REFERENCES}

Abidi, S.S.R. (2006). Healthcare Knowledge Sharing: Purpose, Practices and Prospects. In R.K. Bali, Dwivedi, A. (Ed.), Healthcare Knowledge Management: Issues, Advances and Successes, İçinde (65-86). Springer, Heidelberg.

Alavi, M. and Leidner, D.E. (2001), "Knowledge management and knowledge management systems: conception, foundations and research issues", MIS Quarterly, Vol. 25 No. 1, pp. 107-136.

Bolarinwa, J.A.; Olorunfemi, D. Y. (2009), "Organizational Communication for Organizational Climate and Quality Service in Academic Librarian", Library Philosophy and Practice, 1-5

Brakensiek, F.C., (2002), "Knowledge Management for EHS Professionals", Occupational Health-Safety, January, pp. 72-74.

Bruning, R. H., Schraw, G. J., \& Ronning, R. R. (1999). Cognitive psychology and instruction. Prentice-Hall.

Chang Lee, K., S. Lee and I. W. Kang. "KMPI: measuring knowledge management performance”, Information \& Management, Vol. 42, Issue 3, 2005, pp. 469-482.

Cummings, J.N. (2004), "Work groups, structural diversity, and knowledge sharing in a global organization", Management Science, Vol. 50 No. 3 , pp. 352-364.

Dandridge, T.C., I. Mitroff, W.F. Joyce (1980) “Organizational Symbolism: A Topic to Expand Organizational Analysis”, Academy of Management Review, 5, 77- 82.

De Vries, R. E. ve Hooff B. (2006). 'Explaining knowledge sharing'. Sage Publications. 33, 115-135.

FAA (1999) Strategic Program Plan, Aircraft Maintenance Division \& Office of Aviation Medicine. Electronic version retrieved March 16, 2009 from http://library.erau.edu/guest/find/online-full-text/hfami.htm\#strategic

Federal Aviation Administration (2004) Crew Resource Management, Advisory Circular 120- 51E, Washington, D.C.

Fleming, J.L. ve Monda-Amaya, L.E. (2001). Process Variables Critical for Team Effectiveness. Remedial and Special Education. 22, 158-171.

Garnett, James L; Justin Marlowe ve Sanjay K Pandey, Mar/Apr 2008, "Penetrating the Performance Predicament: Communication as a Mediator or Moderator of Organizational Culture's Impact on Public Organizational Performance", Public Administration Review, 68, 2; ABI/INFORM Global, pp. 266-281

Garvin, A. D. (1993). Building a learning organization. Harvard Business Review, JulyAugust, 78-89.

Galunic, C., Sengupta, K. and Petriglieri, J.L. (2014), “Deus ex machina? Career progress and the contingent benefits of knowledge management systems", European Management Journal, Vol. 32 No. 1, pp. 13-23.

Gibbs, Graham R. (2002) Qualitative Data Analysis: Explorations with NVivo. Open University, Buckingham. ISBN 9780335200849

Gold, A., H. A., Malhotra and A. H. Segars. "Knowledge management: an organizational capabilities perspective", Journal of management information systems, Vol. 18, Issue 1, 2001, pp. 185-214.

Gupta, S., Sharma, S.L., Dutta, K., (2007). Using Knowledge Mapping to Support Knowledge Management in Health Organizations. (24.8.2009). Http://Library.Igcar.Gov.In/Readit2007/Conpro/Htmls/S2.Html.

Grant,R. M. (1996). 'Prospering in dynamically-com-petitive environments: Organizational capability as knowledge integration',Organization Science, 7(4),pp.375-387

Hamel, G. (1999). The quest for value. Executive Excellence. 16(3): 2-13.

Hayashi, A.M. (2004)."Building beter teams". Intelligence. Knowledge Management. 45(2), 5.

Hidalgo, C.A. (2011), "The value in the links: networks and the evolution of organizations", in Allen, P., Maguire, S. and McKelvey, B. (Eds), Sage Handbook on Management and Complexity, Sage, London, pp. 257-569.

Husted, K. and Michailova, S. (2002). Knowledge Sharing in Russian Companies with Western Participation. Management International. Vol. 6 (2), pp. 17-28. 
Hutchison A J, Johnston L H, Breckon J D. Using QSR-NVivo to facilitate the development of a grounded theory project: an account of a worked example. International Journal of Social Research Methodology, 2010, 13(4): 283-302.

Jensen, M. T. (2003). Organizational Communication a Review: Research and Development Report. http://www.agderforskning.no/rapporter/82002046.pdf. Kaynaktan 11/01/2006 tarihinde alınmıştır

Kelly, Dawn, 2000, “Using vision to improve organisational communication”, Leadership \& Organization Development Journal; 21, 1/2; Abı/Inform Global, pp. 92- 101.

Keskin, H., Akgün, AE, Koçoğlu, í. (2016). Örgüt Teorisi (1. Baskı). Ankara: Nobel Yayıncılık.

Kitzinger, J., (1995). Qualitative research: Introducing focus groups. Bmj, 311(7000), 299-302.

Kogut, B. and U. Zander (1992). 'Knowledge of the firm, combinative capabilities, and the replication of technology', Organization Science, 3(3), pp.383-397.

Kuckartz, U., R"adiker, S., 2019. Analyzing Focus Group Data, in: Analyzing Qualitative Data with MAXQDA: Text, Audio, and Video. Springer International Publishing, Cham, pp. 201-217. https://doi.org/10.1007/978-3-030-15671-8_15.

Linn Hsiu-F. and Lee Gwo-G., (2005), "Perceptions Of Senior Managers Toward KnowledgeSharing Behavior”, Management Decision, Emerald Publishing Limited 0025-1747, Vol. 42(1), 74-78.

Marton, F. (1994). In the International Encyclopedia of Education. Second edition, Volume 8. Eds. Torsten Husén \& T. Neville Postlethwaite. Pergamon, $4424-4429$.

MAXQDA,2020. MAXQDA.

Miller, R. (2002). Motivating and managing knowledge workers: blending strategy and culture in knowledge organizations, Knowledge Management Review, 5 (1), 6-19.

Miles, I. (2012). KIBS and knowledge dynamics in client-supplier interactions. In E. Di Maria, R. Grandinetti, \& B. Di Bernardo (Eds.), Exploring knowledge intensive business services (pp. 13-34). London: Palgrave MacMillan.

Nevile M (2006) Communication in Context: a Conversational Analysis Tool for Examining Recorded Data in Investigations of Aviation Occurences, ATSB Research and Analysis Report.

Patton, M. Q. (2002). Qualitative Research and Evaluation Methods. Thousand Oaks, CA, Sage.

Potter, L. R. (2003). The Communicator as Gardener. Communication World, 20(2), 5-14.

Polanyi, M. (1997). The tacit dimension. In L. Prusak (Ed.), Knowledge in organizations (pp. 135-146). Boston: Butterworth-Heinemann.

Riege, Andreas (2005) Three-Dozen Knowledge-Sharing Barriers Managers Must Consider. Journal of Knowledge Management. Vol. 9 No. 3. pp. 18-35.

Saillard, E.K., 2011. Systematic versus interpretive analysis with two CAQDAS packages: NVivo and MAXQDA. Forum Qualitative Sozialforschung/Forum. Qualitative Social Research.

Senge, M. P. (2000). Beşinci disiplin, İstanbul: Yapı Kredi Yayınları. Çevirenler: Ayşegül ildeniz, Ahmet Doğukan.

Senge, P.M. (1990a). The fifth discipline: the arts and practice of the learning organization. New York: Doubleday.

Senge, M. P. (1990). The Leader's New Work: Building Learning Organizations. Sloan Management Review, (Fall), 9-18.

Sexton J B ve Helmreich R L (2000) Analyzing cockpit communication: The links between language, performance, error and workload, Human Performance in Extrem Environments, 5 (1): pp 63-68.

Simon H. A. (1991). Bounded rationality and organizational learning. Organization Science, 2: 125-134.

Steinheider, B., Al-Hawamdeh, S., (2004). Team Coordination, Communication and Knowledge Sharing in Smss and Large Organizations. J. Inf Knowl Manage, 3(3). 223-232.

Taylor, James R. ve Franqois Cooren, (1997). "What makes communication organizational? How the many voices of a collectivity become the one voice of an organization", Journal of Pragmatics, 27, pp. 409-438.

Welsh, E. 2002. "Dealing with Data: Using NVivo in the Qualitative Data Analysis Process [12 paragraphs]." Forum Qualitative Sozialforschung/Forum: Qualitative Social Research 3 (2). 